\title{
Branched-chain amino acids in the treatment of chronic hepatic encephalopathy
}

\author{
L S ERIKSSON, A PERSSON, and J WAHREN* \\ From the Departments of Medicine, Clinical Neurophysiology, and Clinical Physiology, Karolinska Institute, \\ Huddinge University Hospital, Stockholm, Sweden
}

SUMMARY The therapeutic efficacy of orally administered branched-chain amino acids in patients with liver cirrhosis and chronic encephalopathy was examined in a double-blind, randomised crossover study. Seven patients with manifest hepatic cirrhosis and encephalopathy of six months' duration or longer ingested $30 \mathrm{~g}$ branched-chain amino acids or placebo during two 14-day periods. Psychometric tests and electroencephalograms were used to evaluate cerebral function. Neither clinical observations nor psychometric testing or electroencephalogram indicated a significant difference in the patients' response to branched-chain amino acids as compared with placebo. In four patients given branched-chain amino acids for longer periods (five to 22 weeks), psychometric tests also temained unchanged. The plasma concentrations of these acids after oral intake increased significantly, demonstrating adequate absorption. Basal plasma amino acid concentrations were unchanged, however, after branched-chain amino acid therapy. No side-effects were seen, which indicates that these amino acids are well tolerated as an extra protein supply in patients with chronic hepatic encephalopathy. As compared with placebo, however, no effect of branched-chain amino acids on the encephalopathy could be detected.

It has recently been suggested that administration of branched-chain amino acids to patients with liver cirrhosis and encephalopathy may improve cerebral function, thereby offering a new therapeutic approach in this disorder. ${ }^{1-3}$ The biochemical basis for this suggestion is related to the characeristic plasma amino acid pattern found in patients with severe liver cirrhosis: high levels of aromatic amino acids and reduced concentrations of the three branched-chain amino acids, leucine, isoleucine, and valine. ${ }^{45}$ It has been postulated that these alterations, together with an augmented permeability of the blood-brain barrier for neutral amino acids, ${ }^{6}$ result in an increased influx of aromatic amino acids to the brain, thereby eliciting an imbalance in the brain's synthesis of neurotransmitters, particularly serotonin and noradrenaline. ${ }^{78}$ This may result in an accumulation of 'false' neurotransmitters such as octopamine, ${ }^{29}$ which in turn may be responsible for the cerebral dysfunction

* Address for correspondence: Professor John Wahren, Department of Clinical Physiology, Huddinge University Hospital, S-141 86 Huddinge, Sweden.

Received for publication 2 February 1982 associated with hepatic encephalopathy.

Administration of branched-chain amino acids to such patients should increase their concentration in the blood and uptake in the brain, thereby reducing the influx of aromatic amino acids to the brain and normalising neurotransmitter synthesis. Indeed, intravenous administration of these amino acids to patients with hepatic cirrhosis is reported to lower whole blood concentrations and reduce brain uptake of aromatic amino acids. ${ }^{5}$ Recently, it was proposed that ingestion of a diet enriched with branched-chain amino acids may improve chronic hepatic encephalopathy. ${ }^{3}$ This report, however, involved only one patient and no controlled clinical trials with these amino acids have yet been reported concerning cerebral function in patients with hepatic encephalopathy. Therefore, the present study was undertaken to evaluate the efficacy of oral treatment with branched-chain amino acids in patients with cirrhosis and chronic hepatic encephalopathy.

\section{Methods}

PATIENTS

Seven patients, two men and five women, were 
admitted to the study. All had clinical and laboratory evidence of severe liver disease and histologically verified liver cirrhosis of varying aetiology (Table 1). One patient (no. 4) had a surgical portacaval shunt. All patients had been seen regularly at the outpatient clinic and had a history of clinically overt stable chronic hepatic encephalopathy (grade I-II in a IV-graded scale, according to Conn $^{10}$ ) for six months or more (Table 1) and four had abnormal electroencephalograms. No acute precipitating factors - for example, gastrointestinal bleeding, hypokalaemia, etc. - were found in the immediate prestudy period. During the trial the patients maintained the same medical regimen as before the study. Thus, four patients received daily lactulose and were on a protein restricted diet $(40$ g/day) throughout the study. The other three patients ingested $60-100 \mathrm{~g}$ protein per day. Five patients were hospitalised for one to three weeks before and during the study and two were seen as outpatients once or twice weekly. A group of 10 subjects (five hospital employees and five patients, three male and seven female, age 42 to 60 years, mean 52 years) without liver disease or evidence of cerebral dysfunction served as a control group for the psychometric tests. Plasma amino aicd concentrations were determined in six healthy control subjects, two men and four women (aged 48 to 58 years) in the morning after a $12-14$ hour overnight fast. The purpose, nature, and possible risks involved were carefully explained to all patients before obtaining their consent to taking part in the study. The study protocol was reviewed and approved by the local ethical committee.

\section{PROCEDURE}

The patients received either branched-chain amino acids or placebo for 14 days each in a double-blind, randomised crossover study design. The crystalline branched-chain amino acids mixture $(70 \%$ leucine, $20 \%$ valine, and $10 \%$ isoleucine, generously supplied by KabiVitrum, Stockholm, Sweden) was dispensed in sachets $(7.5 \mathrm{~g}$ of the amino acids, $3.7 \mathrm{~g}$ sucrose) and taken orally as powder dissolved in orange juice four times daily $(30 \mathrm{~g} / \mathrm{day})$. The placebo substance consisted of sucrose $(2 \cdot 8 \mathrm{~g})$ and maltodextrine $(8.4 \mathrm{~g})$ and was dispensed and administered in the same way as the amino acids. The hospitalised patients received their sachets from the nurses four times daily, while the two patients at home were given a week's supply of branched-chain amino acids or placebo at their weekly clinic visits. Neither patients nor medical staff could tell the difference between the two substances from their appearance or taste. At the end of the study it turned out that three patients had been treated with branched-chain amino acids and four with placebo during the first test period. After the end of the four-week crossover study, six patients were given the amino acids $(30 \mathrm{~g} /$ day $)$ for five to 22 weeks and were followed as outpatients every third or fourth week.

\section{EEG AND PSYCHOMETRIC TESTS}

Before and at the end of each 14-day treatment period, the patients performed psychometric tests and an EEG was recorded at rest. In four of the six patients receiving long-term treatment with branched-chain amino acids additional psychometric tests were carried out after two to five months of treatment. The tests were conducted by a trained psychologist who was unaware of the patients' treatment. The tests were designed to evaluate visual perception and retention, visual constructive abilities, memory, cognitive motor abilities, and attention and consisted of Benton's test, ${ }^{11}$ Reitan trail making $\mathrm{A}$ and $\mathrm{B},{ }^{12}$ colour test (simplified version of Stroop), ${ }^{13}$ digit symbol test (WAIS), ${ }^{14}$ and the Bourdon-Wirsma test. ${ }^{15}$ Different versions of the tests were used on each test occasion in order to avoid a training effect. The EEG examination consisted of the standard 21 scalp electrodes placed

Table 1 Clinical and laboratory data for patients

\begin{tabular}{|c|c|c|c|c|c|c|c|}
\hline Patient & $\begin{array}{l}\text { Age } \\
(y r)\end{array}$ & Sex & $\begin{array}{l}\text { Aetiology of } \\
\text { cirrhosis }\end{array}$ & $\begin{array}{l}\text { Duration of } \\
\text { encephal- } \\
\text { opathy } \\
\text { (months) }\end{array}$ & $\begin{array}{l}\text { Albumin } \\
(g / l)^{*}\end{array}$ & $\begin{array}{l}\text { Prothrombin } \\
\text { index }{ }^{+}\end{array}$ & $\begin{array}{l}\text { Aspartate } \\
\text { transferase } \\
(\mu k a t / l) \ddagger\end{array}$ \\
\hline 1 & 60 & $\mathbf{M}$ & Cryptogenic & 8 & 24 & 45 & $0 \cdot 73$ \\
\hline 2 & 65 & $\mathbf{F}$ & Nutritional (post ileal by-pass op.) & 8 & 28 & 45 & $0 \cdot 61$ \\
\hline 3 & 54 & $\mathbf{F}$ & Cryptogenic & 12 & 30 & 59 & $0 \cdot 82$ \\
\hline 5 & 57 & $\mathrm{~F}$ & Post-hepatic & 6 & 34 & 68 & 1.85 \\
\hline 6 & 59 & $\mathrm{~F}$ & Alcoholic & 17 & 28 & 49 & $0 \cdot 75$ \\
\hline 7 & 55 & $\mathbf{M}$ & Alcoholic & 24 & 39 & 80 & $1 \cdot 39$ \\
\hline
\end{tabular}

${ }^{*}$ Normal range $38-55 \mathrm{~g} / \mathrm{l} . \quad+$ Normal range $54-104 . \quad \ddagger$ Normal value $<0.7 \mu \mathrm{kat} / \mathrm{l}$. 
according to the 10-20 system. The EEG records were analysed blindly by one reader and the abnormality graded according to a seven degree scale. ${ }^{16}$ EEG and psychometric tests were performed at the same time of the day throughout the study.

\section{AMINO ACID ANALYSES}

Venous blood samples for plasma amino acid analysis and routine clinical biochemistry were obtained before the trial and then once or twice weekly. The blood samples were drawn in the morning with the patients in the postabsorptive basal state at least 12 hours after ingestion of branched-chain amino acids or placebo. Venous blood samples for amino acid levels were also obtained before and at timed intervals for three hours after ingestion of $7.5 \mathrm{~g}$ branched-chain amino acids in five of the patients receiving long-term treatment with these amino acids. Plasma amino acid concentrations were determined using an automated ion-exchange chromatograph (Liquimat III, Kontron, Switzerland) with norleucine as internal standard. The proteins were precipitated with $30 \%$ sulphosalicylic acid within one hour after sampling and the supernatant was stored at $-20^{\circ} \mathrm{C}$ until analysed.

Standard statistical methods have been used, ${ }^{17}$ with the paired $t$ test when applicable.

\section{Results}

Before the trial the patients exhibited varying degrees of difficulty in concentration, abnormal sleep pattern, tiredness, irritability, and personality changes. During the first treatment period the degree of encephalopathy improved in five of the patients (three given branched-chain amino acids and two placebo) - two from grade II to I, three from grade I to 0 , while two were unchanged (grade I). In the second treatment period two patients deteriorated clinically: one patient treated with branched-chain amino acids had a return of difficult concentration, sleep disturbance, and irritability (grade 0 to I), and one patient receiving placebo shifted from grade I to III during the first week (of the second period) and subsequently reverted to grade I within the observation period. The clinical status of the other patients was unchanged. During long-term treatment with branched-chain amino acids one patient deteriorated (grade I to III) and subsequently died in hepatorenal failure after five weeks; the clinical status of the other patient remained unchanged.

The results from the psychometric testing before the therapeutic trial and after the two treatment modalities (branched-chain amino acids and placebo) are presented in Table 2. As expected, the patients' test results before the trial were significantly poorer than those for the controls in all six tests, indicating the presence of cerebral dysfunction in the patients. The influence of administration of these amino acids on the patients' cerebral function may be evaluated by comparing the psychometric test results obtained after branched-chain amino acids and placebo administration, respectively. No statistically significant difference is seen for any single test (Table 2). The results obtained with either branched-chain amino acids or placebo as compared with the pre-trial values, however, revealed significant improvements in the case of three of the psychometric tests (trail making A, digit symbol, and Bourdon-Wirsma). These improvements were apparent during the first test period and remained at the same level after the second period, irrespective of whether branched-chain amino acids or placebo was administered. The psychometric test results also failed to show any further improvement in the four patients studied after five to 22 weeks of continuous treatment with these amino acids.

Before the trial four patients showed a definitely abnormal EEG, two of which were of characteristic pre-coma appearance. During branched-chain amino acids administration the EEG improved in two patients, deteriorated in one, and showed an unchanged pattern in four. When placebo was given improvements were seen in three patients and deterioration in one. Two patients with normal EEGs showed unchanged patterns during both treatment periods.

Table 2 Psychometric test results in controls and patients with hepatic encephalopathy before and after 14 days of $B C A A$ and placebo, respectively*

\begin{tabular}{|c|c|c|c|c|}
\hline \multirow[b]{2}{*}{ Test } & \multirow[b]{2}{*}{ Controls } & \multicolumn{3}{|l|}{ Patients } \\
\hline & & $\begin{array}{l}\text { Before } \\
\text { treatment }\end{array}$ & $\begin{array}{l}\text { After } \\
B C A A\end{array}$ & $\begin{array}{l}\text { After } \\
\text { placebo }\end{array}$ \\
\hline \multicolumn{5}{|l|}{ Trail making (s) } \\
\hline $\begin{array}{l}\text { A } \\
\text { B }\end{array}$ & $\begin{array}{c}48 \pm 5 \S \\
103 \pm 10 \dagger\end{array}$ & $\begin{array}{r}90 \pm 9 \\
142 \pm 8\end{array}$ & $\begin{array}{r}59 \pm 9 \ddagger \\
127 \pm 15\end{array}$ & $\begin{array}{l}53 \pm 12+ \\
126 \pm 15\end{array}$ \\
\hline \multicolumn{5}{|l|}{ Benton } \\
\hline No. correct & $7 \pm 0.4 \ddagger$ & $4 \cdot 0 \pm 1 \cdot 0$ & $4 \cdot 4 \pm 1 \cdot 0$ & $4 \cdot 6 \pm 1 \cdot 0$ \\
\hline Error score & $4 \cdot 6 \pm 1 \cdot 1 \dagger$ & $12 \cdot 4 \pm 3 \cdot 1$ & $11 \cdot 1 \pm 2 \cdot 2$ & $10 \cdot 3 \pm 2 \cdot 9$ \\
\hline Colour test (s) & $32 \pm 2 \ddagger$ & $76 \pm 16$ & $58 \pm 16$ & $54 \pm 16$ \\
\hline $\begin{array}{l}\text { Bourdon-Wirsma } \\
\text { (no. correct) }\end{array}$ & $226 \pm 21+$ & $130 \pm 30$ & $185 \pm 32 \ddagger$ & $192 \pm 32 \dagger$ \\
\hline $\begin{array}{l}\text { Digit symbol } \\
\text { (no. correct) }\end{array}$ & $93 \pm 8+$ & $49 \pm 14$ & $62 \pm 14 \dagger$ & $65 \pm 13$ \\
\hline
\end{tabular}


As expected, the plasma amino acid concentrations in the basal, postabsorptive state showed an abnormal pattern: low levels of branched-chain amino acids and raised concentrations of tyrosine, phenylalanine, and methionine (Table 3). No consistent changes were subsequently seen in the basal amino acid levels during either the two week crossover study or after prolonged administration of branched-chain amino acids (Table 3 ).

The concentrations of plasma amino acids immediately after oral ingestion of $7.5 \mathrm{~g}$ of branched-chain amino acids are shown in the Figure. All three branched-chain amino acids increased by a maximum of two to eight fold and returned to baseline by two to three hours. In contrast there was a consistant fall in the levels of tyrosine $(-35 \%)$, phenylalanine $(-55 \%)$, and methionine $(-60 \%)$. These concentrations remained depressed for at least three hours after branched-chain amino acids ingestion in all five patients studied.

No significant changes were seen in the serum concentrations of albumin, creatinine, electrolytes, or liver enzymes during the crossover study.

\section{Discussion}

The present trial was designed to study the effect of branched-chain amino acids on cerebral function in patients with liver cirrhosis and chronic encephalopathy. Thus, $30 \mathrm{~g}$ of branched-chain amino acids was added to the patients' regular diet. As is evident from Table 2, none of the six psychometric tests showed a difference in the patients' response to these amino acids as compared with placebo administration. Moreover, neither the clinical findings nor the EEG results suggested a more beneficial effect of branched-chain amino acids than of placebo.

These findings are not in accord with a recent report by Freund et al. ${ }^{3}$ In a single patient with hepatic cirrhosis and chronic encephalopathy, a branched-chain amino acid-enriched diet $(8.5 \mathrm{~g}$ daily) was associated with an improvement in the clinical status and EEG after one or two weeks of treatment. In the present study, however, five of the seven patients improved during the first test period, irrespective of whether they received branchedchain amino acids or placebo. Thus, hospitalisation, increased clinical attention, etc., are probably of importance in this context and the positive effect of branched-chain amino acids in the above mentioned report may in part be attributed to such factors.

A pertinent question is whether the administered amino acids were, in fact, absorbed. Serial measurements within three hours after ingestion of one quarter of the daily branched-chain amino acid dosage revealed a substantial rise in leucine, valine, and isoleucine concentrations as well as a marked diminution in the levels of tyrosine, phenylalanine, and methionine. We may thus conclude that ingestion of these amino acids was accompanied by their rapid gastrointestinal absorption and raised plasma levels, as well as a fall in the levels of aromatic amino acids similar to that reported to accompany intravenous branched-chain amino acid infusion. $^{5}$

The study period in the present trial was set at 14 days on the assumption that this would be sufficient to reveal any positive effects of branched-chain amino acids ingestion. For patients with acute hepatic coma, improvement is said to occur within the first one or two days of this treatment. ${ }^{1}$ Patients with longstanding encephalopathy, however, may require a longer period of treatment before any improvement can be seen. In the patient reported by Freund $e t a l^{3}$ the first signs of improved cerebral function were seen after one week. In order to examine the possibility of a long-term effect, six of the present patients received branched-chain amino

Table 3 Venous plasma amino acid concentrations in post-absorptive state for controls versus patients before treatment, after 14 days of BCAA or placebo administration and after 5-22 weeks of BCAA treatment*

\begin{tabular}{|c|c|c|c|c|c|}
\hline & \multirow[b]{2}{*}{ Controls } & \multicolumn{4}{|l|}{ Patients } \\
\hline & & $\begin{array}{l}\text { Before } \\
\text { treatment }\end{array}$ & $\begin{array}{l}\text { During } \\
B C A A\end{array}$ & $\begin{array}{l}\text { During } \\
\text { placebo }\end{array}$ & $\begin{array}{l}\text { Prolonged } \\
B C A A\end{array}$ \\
\hline $\begin{array}{l}\text { Valine } \\
\text { Isoleucine } \\
\text { Leucine } \\
\text { Methionine } \\
\text { Tyrosine } \\
\text { Phenylalanine }\end{array}$ & $\begin{array}{c}216 \pm 21 \dagger \\
68 \pm 89 \\
133 \pm 11 \dagger \\
28 \pm 29 \\
60 \pm 4 \dagger \\
54 \pm 4 \S\end{array}$ & $\begin{array}{c}135 \pm 16 \\
41 \pm 6 \\
80 \pm 9 \\
41 \pm 4 \\
111 \pm 12 \\
86 \pm 5\end{array}$ & $\begin{array}{l}135 \pm 15 \\
45 \pm 5 \\
86 \pm 9 \\
39 \pm 3 \\
99 \pm 18 \\
82 \pm 9\end{array}$ & $\begin{array}{c}106 \pm 149 \\
37 \pm 5 \\
65 \pm 79 \\
36 \pm 3 \\
101 \pm 13 \\
79 \pm 7\end{array}$ & $\begin{array}{c}102 \pm 17 \\
37 \pm 8 \\
68 \pm 14 \\
40 \pm 7 \\
108 \pm 17 \\
83 \pm 7\end{array}$ \\
\hline
\end{tabular}

* Data are given as mean $\pm \mathrm{SE}$ in $\mu \mathrm{mol} / \mathrm{l}$.

$+\mathrm{p}<0.01$, \ $\mathrm{p}<0.05, \S \mathrm{p}<0.001$, as compared with the corresponding value in patients before treatment. 


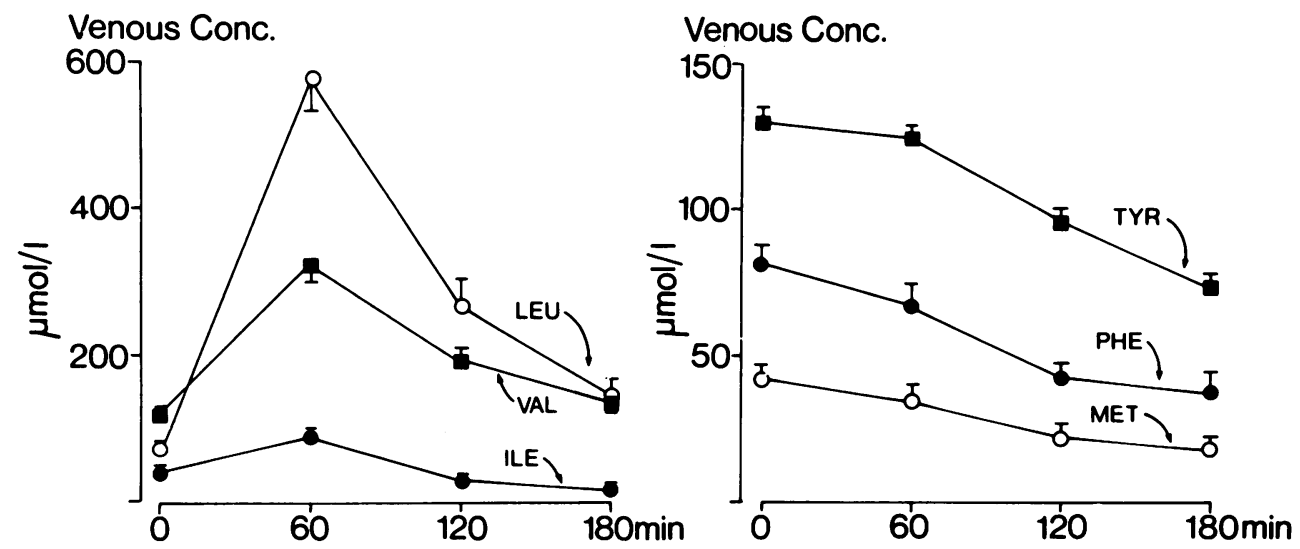

Figure Plasma amino acid concentrations after ingestion of branched-chain amino acids (7.5 g). Data are given as mean $\pm S E$.

acids, $30 \mathrm{~g}$ daily, for five to 22 weeks after the initial trial. No further improvement was noted, however, either in the patients' symptoms or in the psychometric test results. Thus, neither brief nor prolonged periods of branched-chain amino acids treatment appear capable of influencing the encephalopathy in these patients.

It should be noted that, while administration of branched-chain amino acids raised postprandial plasma levels of these amino acids (Figure), the basal concentrations of branched-chain amino acids and aromatic amino acids remained unchanged (Table 3). This was true after either two weeks or more prolonged (five to 22 weeks) treatment with these amino acids. Given the rapid decline in plasma branched-chain amino acids which occurs after an oral load (Figure), one cannot expect that an oral regimen will restore normal basal plasma amino acid concentrations. The improvement in patients with hepatic coma observed after intravenous branchedchain amino acids ${ }^{1}$ may thus be a consequence of continuous administration of amino acids and normalisation of the plasma amino acid profile throughout the day.

The experimental design used in the current study involved an increased amino acid intake of $30 \mathrm{~g} /$ day during this treatment. Although no comparable increase in mixed protein administration was given during the placebo period, the possibility cannot be excluded that branched-chain amino acids were in fact less toxic (with respect to psychometrics or EEG) than an isonitrogenous load of protein. In the present study utilisation of these amino acids was not examined, but, as no side-effects were observed, branched-chain amino acids might conceivably constitute a means of increasing nitrogen intake in cirrhotic patients without causing a deterioration in encephalopathy. On the other hand, the data clearly indicate that, compared with a nitrogen-free placebo, the branched-chain amino acids regimen fails to improve cerebral function.

The suggestion that 'false' neurotransmitters may be of pathogenetic importance for hepatic encephalopathy has received much attention recently. Findings concerning brain concentrations of catecholamines and octopamine, however, show no significant differences between patients with hepatic encephalopathy and control patients. ${ }^{18}$ Moreover, preliminary results from a controlled study involving intravenous infusion of branched-chain amino acids in patients with hepatic coma demonstrate no positive influence on consciousness when compared with ordinary amino acid solutions. ${ }^{19}$ The results from the present study are in accordance with these findings - no tendency to improvement after oral administration of branched-chain amino acids.

\section{ADDENDUM}

The findings in a recent study by McGhee $e t l^{20}$ in which cirrhotic patients ingested a branched-chain amino acid enriched diet support the conclusion of the present report that these amino acids fail to exert a beneficial effect on hepatic encephalopathy.

This study was supported by grants from the Swedish Medical Research Council (No. 3108), Petrus and Augusta Hedlund Foundation, and the Karolinska Institute, Stockholm, Sweden. We are indebted to psychologist Dan Andreasson for skilfully performing the psychometric tests and to 
Professor Daisy Schalling, Department of Psychiatry, Karolinska Hospital, Stockholm, for assistance in designing the psychometric test battery and to the physicians who kindly submitted patients to the trial.

\section{References}

1 Fischer J, Rosen H, Ebeid A, James H, Keane J, Soeters P. The effect of normalization of plasma amino acids on hepatic encephalopathy in man. Surgery 1976; 80: 77-91.

2 Smith A, Rossi-Fanelli F, Ziparo V, James H, Perelle $B$, Fischer $J$. Alterations in plasma and CSF amino acids, amines and metabolites in hepatic coma. Ann Surg 1978; 187: 343-50.

3 Freund H, Yoshimura N, Fischer J. Chronic hepatic encephalopathy. Long-term therapy with a branchedchain amino-acid-enriched elemental diet. JAMA 1979; 27: 347-9.

4 Iber F, Rosen H, Levenson S, Chalmers T. The plasma amino acids in patients with liver failure. $J$ Lab Clin Med 1957; 50: 417-25.

5 Sato Y, Eriksson S, Hagenfeldt L, Wahren J. Influence of branched-chain amino acid infusion on arterial concentrations and brain exchange of amino acids in patients with hepatic cirrhosis. Clin Physiol 1981; 1: 151-65.

6 James H, Escourrou J, Fischer J. Blood-brain neutral amino acid transport activity is increased after portacaval anastomosis. Science 1978; 200: 1395-7.

7 Dodsworth J, James H, Cummings M, Fischer J. Depletion of brain norepinephrine in acute hepatic coma. Surgery 1974; 75: 811-20.

8 Knell A, Davidson A, Williams R, Kantamaneni, B, Curzon G. Dopamine and serotonin metabolism in hepatic encephalopathy. Br Med J 1974; 1: 549-51.

9 Fischer J, Baldessarini R. False neurotransmitters and hepatic failure. Lancet 1971; 2: 75-9.
10 Conn HO, Lieberthal MM. The hepatic coma syndromes and lactulose. Baltimore: Williams and Wilkins, 1979: 5-8.

11 Benton AL. The revised visual retention test. Iowa City: State University of Iowa, 1963.

12 Reitan RM. Validity of the trail making test as an indicator of organic brain damage. Percept Mot Skills 1958; 8: 271-6.

13 Smith GJW, Nyman GE. Manual till CWT-serialt. Stockholm: Scandinaviska testförlaget, 1972.

14 Mirsky A, Kornetsky C. On the dissimilar effects of drugs on the digit symbol substitution and continuous performance tests. Psychopharmacologia 1964; 5: 16177.

15 Mindus P, Cronholm B, Levander SE, Schalling D. Piracetam-induced improvement of mental performance. A controlled study on normally aging individuals. Acta Psychiatr Scand 1976; 54: 150-60.

16 Kellaway P. An orderly approach to visual analysis: parameters of the normal EEG in adults and children. In: Klass DW, Daly DD, eds. Current practice of clinical electroencephalography. New York: Raven Press, 1979: 69-147.

17 Snedecor GW, Cochran WG. Statistical methods. Ames: Iowa State University Press, 1967.

18 Cuilleret G, Pomier-Layrargues G, Pons F, Cadilhac J, Michel $\mathbf{H}$. Changes in brain catecholamine levels in human cirrhotic hepatic encephalopathy. Gut 1980; 21: 565.

19 Michel H, Pomier-Layrargues G, Duhamel O, Lacombe B, Guilleret $\mathrm{G}$, Bellet $\mathrm{H}$. Intravenous infusion of ordinary and modified amino acid solutions in the management of hepatic encephalopathy (controlled study, 30 patients). (Abstract.) The Amercian Association for the Study of Liver Diseases. 31 st annual meeting, November 5-6, and November 7-8, 1980.

20 McGhee N, Hendersen JM, Milliken WJ, Bleir J. Comparison of the effect of Hepaticaid and casein modular diets on encephalopathy, plasma amino acids and nitrogen balance in cirrhotic patients. Ann Surg 1982 ; in press. 